\title{
Deletion of $P k d 1$ in renal stromal cells causes defects in the renal stromal compartment and progressive cystogenesis in the kidney
}

\author{
Xuguang $\mathrm{Nie}^{*}$ and Lois J Arend
}

\begin{abstract}
Autosomal dominant polycystic kidney disease (ADPKD), caused by PKD1 and PKD2 gene mutations, is one of the most common genetic diseases, affecting up to 1 in 500 people. Mutations of PKD1 account for over 85\% of ADPKD cases. However, mechanisms of disease progression and explanations for the wide range in disease phenotype remain to be elucidated. Moreover, functional roles of PKD1 in the renal stromal compartment are poorly understood. In this work, we tested if $P k d 1$ is essential for development and maintenance of the renal stromal compartment and if this role contributes to pathogenesis of polycystic kidney disease using a novel tissue-specific knockout mouse model. We demonstrate that deletion of $P k d 1$ from renal stromal cells using Foxd1-driven Cre causes a spectrum of defects in the stromal compartment, including excessive apoptosis/proliferation and extracellular matrix deficiency. Renal vasculature was also defective. Further, mutant mice showed epithelial changes and progressive cystogenesis in adulthood modeling human ADPKD. Altogether, we provide robust evidence to support indispensable roles for $P k d 1$ in development and maintenance of stromal cell derivatives by using a novel ADPKD model. Moreover, stromal compartment defects caused by Pkd 1 deletion might serve as an important mechanism for pathogenesis of ADPKD.
\end{abstract}

Laboratory Investigation (2017) 97, 1427-1438; doi:10.1038/labinvest.2017.97; published online 11 September 2017

Autosomal dominant polycystic kidney disease (ADPKD) is one of the most common genetic diseases, affecting up to 1 in 500 people. Most individuals affected by ADPKD proceed to end-stage renal disease (ESRD) by the fifth and sixth decades. ADPKD is caused by mutations in PKD1 and/or PKD2 genes, which encode polycystin-1 (PC1) and polycystin-2 (PC2), respectively. Mutations of $P K D 1$ gene account for over $85 \%$ of ADPKD cases; the rest are attributable to mutations of $P K D 2$. Although a causative role of gene mutations has been firmly established, the mechanisms for disease progression and variations remain obscure.

The current opinion for genetic explanation of PKD is that a germ line mutation coupled with somatic 'second-hit' mutations in the other allele of an ADPKD gene initiate cyst formation. In support of this view, loss of heterozygosity has been detected in cyst lining cells of ADPKD kidneys. ${ }^{1,2}$ Recently, it has been shown that dosage change of polycystins is also a critical factor governing cystogenesis and disease severity. ${ }^{3-5}$ In addition, a 'third hit' may also play a role in pathogenesis in ADPKD. ${ }^{6,7}$ Multiple lines of evidence indicate that $P k d 1$-encoded polycystins, located on the renal epithelia, act as fluid flow sensors and regulate calcium inflow via interaction with $P k d 2$-encoded polycystins, which serve as non-selective ion channels for numerous cell types. ${ }^{8-13}$ Loss of flow sensing function in renal epithelial cells might serve as an important mechanism for cyst formation in ADPKD. ${ }^{12-16}$ A number of studies also imply that the primary cilia, where both $P k d 1$ - and $P k d 2$-encoded polycystins co-localize, play a critical role in flow sensing function. ${ }^{12-16}$

However, evidence from recent studies challenges the proposed roles of cilia in cystogenesis, as disrupting cilia in adulthood does not induce significant renal cyst formation. ${ }^{17,18}$ Recent studies indicate that cilia are not mechanosensors, and intact cilia, in the setting of polycystin loss, actually promote cystogenesis. ${ }^{19,20}$ Also, studies with gene targeting approaches show that the severity of polycystic kidney disease (PKD) depends on the time point of gene loss. Disruption of an ADPKD gene in a postnatal stage later than 13 days postpartum (dpp) causes slow cyst formation over a long time period in mice. ${ }^{21-23}$ Altogether, new and emerging

Department of Pathology, Johns Hopkins University, Baltimore, MD, USA

Correspondence: Dr X Nie, PhD, Department of Pathology, Johns Hopkins University, Ross 632 E, 720 Rutland Ave, Baltimore, MD 21205, USA or Dr LJ Arend, MD, PhD, Department of Pathology, Johns Hopkins University, 600 N. Wolfe St, Pathology 709, Baltimore, MD 21287, USA.

E-mail: Xuguang.Nie@gmail.com or ljarend@jhu.edu

*Current address: Center for Craniofacial Regeneration (CCR), School of Dental Medicine, Columbia University, 630 W. 168 St. VC12-211, New York, NY 10032, USA.

Received 6 March 2017; revised 29 June 2017; accepted 2 August 2017 
evidence argues against the flow sensing theory and suggests that other mechanisms also play a role in cyst formation.

Indeed, besides flow sensing, PC1 is implicated in a plethora of cellular activities, including adhesion, extracellular matrix (ECM) regulation, cell signaling, and metabolism. ${ }^{24-26}$ In accordance with these biological activities, PC1 is seen in a variety of non-epithelial cell types and disrupting $P k d 1$ in these tissues leads to defective organogenesis or malfunction in a number of organ systems. ${ }^{27-30}$ In the kidney, less well recognized is the function of $\mathrm{PC} 1$ in stromal cells and their derivatives, which show dynamic PC1 expression in both developing and adult kidneys. ${ }^{29,31-33}$

Renal stromal cells are initially a subpopulation of mesenchymal cells in the embryonic renal blastema. These progenitor cells subsequently differentiate into fibroblasts, mesangial cells, pericytes, and smooth muscle cells to form a set of supportive tissues, including the renal capsule, interstitium, glomerular mesangial stalk, and vascular wall. ${ }^{34-36}$ These stromal cell derivatives are critical to maintain structural integrity and proper function of the renal epithelium and endothelium. ${ }^{3-37}$ Stromal compartment defects are common in ADPKD. ${ }^{32,38}$ Apoptosis, microvasculature obliteration, ECM dysregulation, and fibrosis are hallmarks of stromal compartment changes in ADPKD, and these defects likely play an important role for renal pathogenesis. ${ }^{32,38}$ Even so, there is a lack of direct evidence to establish a functional role of PKD1 for stromal cell derivatives in the kidney. Also, it remains to be tested if stromal compartment defects play a causative role for cyst initiation in ADPKD. In this work, we demonstrate that disruption of $P k d 1$ in renal stromal cells using Foxd1-driven Cre causes diverse defects in stromal cell derivatives, and these defects likely contribute significantly to pathogenesis of PKD.

\section{MATERIALS AND METHODS}

\section{Mice and Knockout Strategy}

Animal use protocol was approved by Johns Hopkins University Animal Care and Use Committee. All the experimental procedures were performed in accordance with the relevant guidelines and regulations of Johns Hopkins University. $P k d 1^{\text {lac } Z /+}$ and $P k d 1^{\operatorname{Lox} P / L o x P}$ mice were described elsewhere. ${ }^{39,40}$ Foxd1 $1^{\text {eGFP-Crel+ }}$ (Foxd1 ${ }^{\text {Crel+ }}$ in figures and figure legends) mouse was purchased from the Jackson lab (stock number: 012463). ${ }^{34}$ Mice were maintained in a mixed background. Genotyping was performed by general PCR. Primers are listed in the webpage of Jackson lab. To inactivate $P k d 1$ in the stromal cell derivatives, we first established Foxd $1^{\text {GGFP-Cre/+}} ; \mathrm{Pkd1}^{\mathrm{LacZ} /+}$ and Foxd $1^{\mathrm{GFP}-\mathrm{Cre} /+} ; \mathrm{Pkd}^{\mathrm{Loxp} /+}$ double heterozygous mice, respectively, which were viable and fertile. We then used the male mice to cross with $P k d 1^{\text {LoxP/LoxP }}$ female mice to generate Foxd $1^{\text {GFF-Cre/+ }} ; P k d 1^{\text {LoxP/LoxP }}$ and Foxd $1^{\text {eGFP-Cre/+}} ;$ Pkd1 ${ }^{\text {LacZ/LoxP }}$ mutant mice, respectively.

\section{Gross Examination, Histology, LacZ Staining, Masson's Trichrome Staining, Immunofluorescence, and Immunohistochemistry}

Gross examination of kidneys was performed under a stereomicroscope on both sides; visible renal cysts were counted at successive stages, three mice for each stage. Tissue preparation for histologic studies was performed using standard procedures. Sagittal sections from paraffinembedded kidney tissues were used in this study. Kidney cyst was defined as a dilated tubule with a diameter at least five times that of normal tubules. Cyst index was determined using a series of sections at a $50 \mu \mathrm{m}$ interval for each mutant kidney; three kidneys from three mice were used for each stage. Low power images were captured and gridded with the Image J software. Cyst index was calculated by the percentage of grid squares counted in cystic areas versus total kidney squares.

Masson's trichrome staining was performed following manufacturer's protocol (Sigma). LacZ staining was described elsewhere. ${ }^{37}$ Immunohistochemistry and immunofluorescence were performed with standard procedures. Antigen retrieval was heat-induced in sodium citrate solution $(\mathrm{pH}$ 6.0). DBA lectin (Sigma), antibodies for PC1 (Sigma), E-cadherin (Cell Signaling), pan-cadherin (Abcam), Laminin (Sigma), pan-cytokeratin (Sigma), type I collagen alpha 1 (Sigma), type IV collagen alpha 1 (Sigma), $\beta$-catenin (Sigma), $\alpha$-smooth muscle actin (Sigma), CD31 (Chemicon), and vimentin (Abcam) were used for immunodetection on sections. First antibodies were incubated overnight at $4{ }^{\circ} \mathrm{C}$. Secondary antibodies were either peroxidase or alkaline phosphatase conjugated for immunohistochemistry (Sigma). DAB (Abcam) was used for peroxidase-mediated color reaction. NBT/BCIP (Roche) was used for alkaline phosphatase-mediated color reaction. For immunofluorescence, Alexa Fluor secondary antibodies were used (Thermo Fisher Scientific). Secondary antibodies were incubated for $2 \mathrm{~h}$ at room temperature. Sections were counterstained with Dapi. Quantification of vimentin-stained areas was performed with Image J. Areas of interest were selected by image thresholding.

\section{Apoptosis and Proliferation Assay}

Paraffin sections were used for TUNEL staining and proliferation assays. TUNEL staining for apoptosis was performed following the manufacturer's protocol. DeadEnd Colorimetric TUNEL System were used in this study (Promega).The fraction of positive staining cells over total number of cells was calculated and used for apoptosis index. The phospho-Histone H3 antibody (Millipore) was used for proliferation assay. The fraction of phospho-Histone H3positive cells over total number of cells was calculated with Image $J$ and used for proliferation index. Two representative and comparable mid-sagittal sections from each kidney were selected, and three mice of each genotype were used for assessment. 


\section{RT-PCR and Real-Time PCR}

Total RNA was isolated from kidneys of three mice for each genotype using Purelink RNA mini kit (Life Technologies), following the manufacturer's instructions. Reverse transcription was performed using High Capacity RNA-to-DNA kit (A\&B Applied Biosystems). Primers for $\beta$-catenin were described elsewhere and confirmed with RT-PCR. ${ }^{30}$ The real-time PCR step was performed in a CFX Touch real-time PCR detecting system (Bio-Rad). Fluorescence was acquired at each cycle. Ct values were normalized to that of GAPDH. Product specificity was confirmed by melting curve analysis.

\section{Western Blot}

Three mice from each genotype were used for western Blot analysis. Kidneys were homogenized in RIPA buffer containing protease inhibitors (50 $\mu \mathrm{l}$ RIPA per $1 \mathrm{mg}$ tissue). The homogenates were left on ice for $30 \mathrm{~min}$, then heated at $95^{\circ} \mathrm{C}$ for $5 \mathrm{~min}$, and spun down at $11000 \mathrm{~g}$ for $15 \mathrm{~min}$. The supernatants were collected for western blot. About $40 \mu \mathrm{g}$ of protein was loaded per lane. Protein transfer was performed using a semi-dry system. HRP-mediated ECL signal was detected by the Kodak Digital Image Station 4000R. Western blots of mutants and controls were semiquantified by comparing their relative density with Image J.

\section{Blood Urea Nitrogen (BUN) Test}

Five mice from each genotype were used for blood urea nitrogen (BUN) test. Blood was collected from mouse facial veins. Blood samples were left at room temperature for half hour, and centrifuged at 5000 r.p.m. for $10 \mathrm{~min}$. Blood serum was sent to the Phenotype Core (Johns Hopkins University) for BUN test.

\section{Statistical Analysis}

All quantitative data were analyzed by two-tailed $t$-test using Microsoft Excel. $P \leq 0.05$ was considered statistically significant.

\section{RESULTS \\ Disruption of Pkd1 Using Foxd1-Driven Cre Leads to Progressive Cystogenesis in Adulthood}

Accumulating evidence demonstrates that $P k d 1 / \mathrm{PC} 1$ is expressed in multiple cell types in the kidney. Besides robust expression in the epithelium, $P k d 1 / \mathrm{PC} 1$ has also been detected in stromal cell derivatives in a number of studies. ${ }^{29,31-33}$ Here, we provide new evidence to support this observation. LacZ staining of $P k d 1^{\text {LacZ/+ }}$ kidneys showed that, along with a high level of $P k d 1$ expression in the epithelial cells, there was moderate expression of $P k d 1$ in the interstitial tissue beginning at mid-gestation (Figure $1 \mathrm{a}$ and $\mathrm{b}$ ). This expression persisted to postnatal stages (data not shown), suggesting a role in stromal compartment development. Similarly, antibody staining showed that, besides epithelial expression, PC1 was consistently detected in stromal cells at a medium level at both embryonic and postnatal stages (Figure $1 \mathrm{c}-\mathrm{q}$ ). Co- localization of PC1 with the mesenchymal marker vimentin confirmed that PC1 was indeed present in interstitial mesenchymal cells in both cortex and medulla (Figure $1 \mathrm{f}-\mathrm{h}$ and $1-n)$.

We next examined the Foxd $1^{\text {GGFP-Cre/+ }} ; P k d 1^{\text {LoxP/LoxP }}$ and Foxd $1^{\text {eGFP-Cre/+}} ;$ Pkd $11^{\text {LacZ/LoxP }}$ mutant mice. A majority of mutant mice survived to adulthood and were infertile, but a significant number of mutant mice died in early adulthood due to extra-renal problems (Figure 2a). Phenotype of these two lines of mutants was similar, except that the phenotype of Foxd1 ${ }^{e G F P-C r e /+} ; P k d 1^{\text {LoxP/LoxP }}$ mice was less severe (Figure $2 \mathrm{a}-\mathrm{d})$. We then performed detailed phenotypic analysis of Foxd ${ }^{\text {GFFP-Cre/+ }}$;Pkd ${ }^{\text {LacZ/LoxP }}$ mutant mice, which carry a null $P k d 1$ allele mimicking human ADPKD and a floxed $P k d 1$ allele that is disrupted in stromal cell derivatives. Foxd $1^{\text {GFFP- }}$ ${ }^{\mathrm{Cre} /} ; P k d 1^{\text {LacZ/LoxP }}$ mice were found at an expected ratio at $14 \mathrm{dpp}$, suggesting that inactivation of Pkd1 using Foxd1driven Cre did not cause embryonic or early postnatal lethality. Mutant mice displayed unique craniofacial features, including dome-shaped heads, short snouts and malocclusion (Figure $2 \mathrm{a}$ and Table 1).

Kidney development in mutant mice was comparable to littermate controls in embryonic and early postnatal stages, suggesting a dispensable role of $\mathrm{PC} 1$ in the stromal compartment for early kidney development. During early postnatal development (3-5 weeks), we detected small cysts in mutant kidneys only by histological examination (data not shown). Progressive cytogenesis continued into adulthood (Figure 2c). In young adult mice, cysts became visible by gross observation (Figure 2c). Examination with histological methods showed isolated cysts in the renal cortex and medulla (Figure 2e and f). Collecting ducts in the medulla were slightly dilated compared with controls (Figure $2 \mathrm{~g}$ and $\mathrm{h}$ ), whereas other tubules remained comparable at this stage (Figure $3 a$ and $b$ ). With maturation, cyst clusters became common in the renal cortex (Figure $3 \mathrm{c}$ and $\mathrm{d}$ ) and cyst number and size steadily increased in mutant mice (Figure $2 \mathrm{c}$ and Figure $3 \mathrm{i}$ ). Kidney to body weight ratios of mutant mice were also significantly increased at the age of 48 and 72 weeks (Figure 3i).

To determine tissue origins of the cysts, we performed dual immunostaining with E-cadherin antibody and DBA lectin, which label the distal tubules of the nephrons and collecting ducts respectively. ${ }^{41,42}$ At 6-weeks, DBA lectin labeled a majority of the cysts suggesting that cysts predominantly arise from the collecting ducts in early life (Figure $3 e$ and f). Later, cystic dilation was also seen in other tubules and glomeruli (Figure $3 \mathrm{~g}$ and $\mathrm{h}$ ). At 24 weeks, the number of cysts derived from the collecting ducts and tubules became comparable (Figure 3j). However, the number of cysts derived from the glomeruli remained low (Figure $3 \mathrm{j}$ ).

We examined kidney function of mutant mice by measuring BUN levels. BUN levels were comparable between mutants and controls until 72 weeks of age, when we started to detect increased BUN levels in mutant mice suggesting that kidney function declined in aged mice (Figure 3k). 


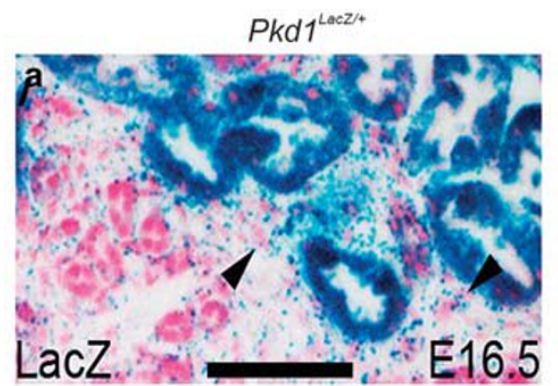

PC1/Dapi
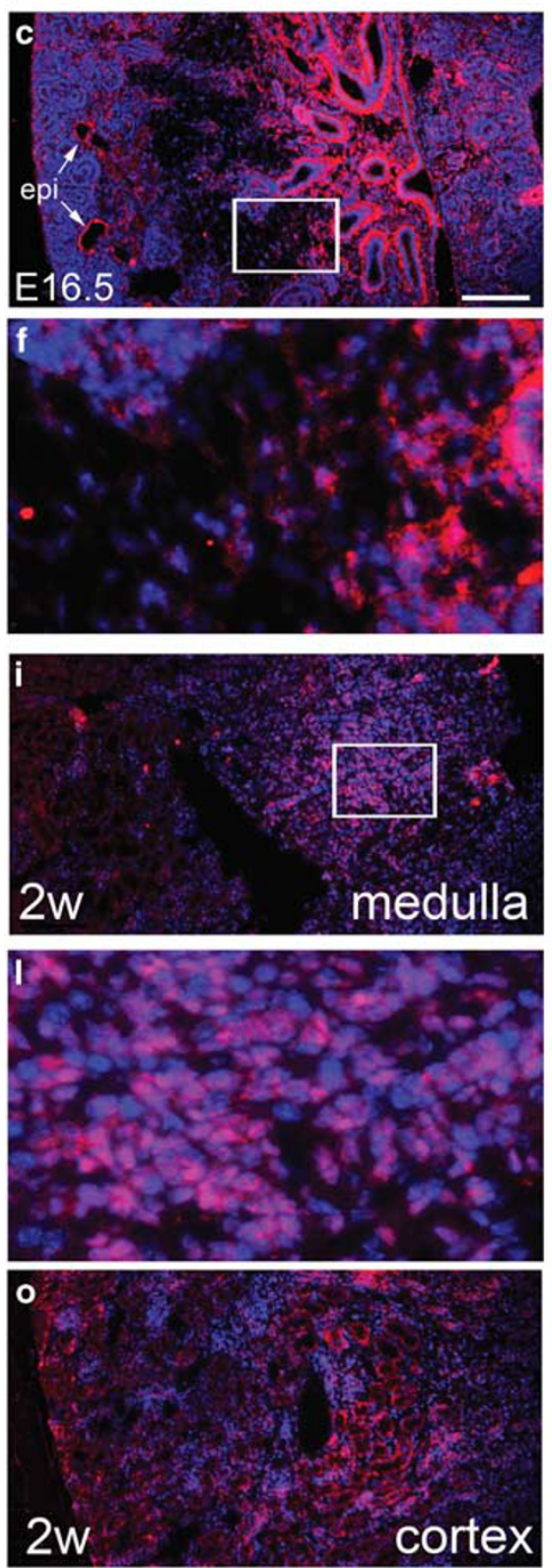

Pkd1 $1^{\text {Lacz/* }}$

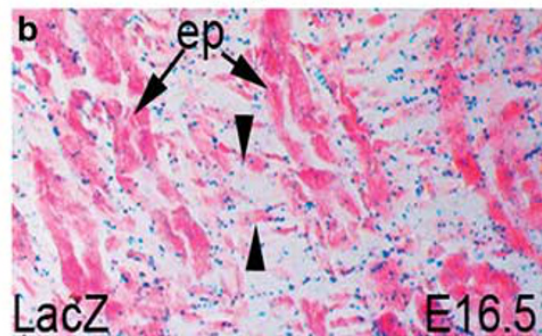

vmt/Dapi
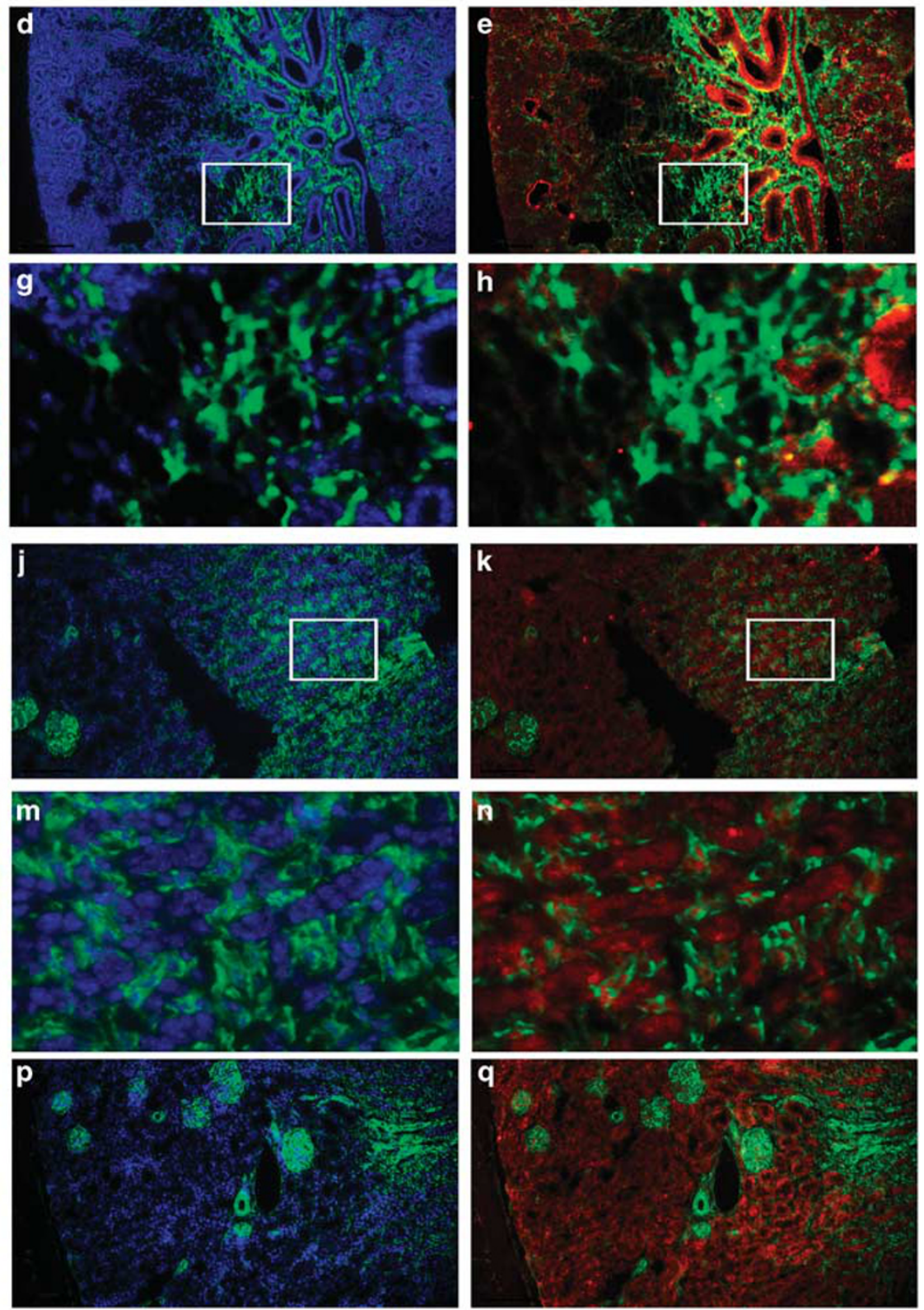

Figure 1 PC1 expression in kidneys. (a) Section of a LacZ-stained $P k d 1^{L a c Z /+}$ kidney, indicating expression of $P k d 1$ in epithelial tubules and interstitial cells in the renal cortex. (b) Section of a LacZ-stained $P k d 1^{\text {LacZ/+ }}$ kidney, indicating expression of $P k d 1$ in stromal cells in the renal medulla. (c-e) Immunofluorescence for PC1 and vimentin in an E16.5 kidney. showing presence of PC1 in both epithelium and stromal compartment. (f-h) Higher magnification of outlined area in (c-e), respectively, showing PC1 in stromal cells. (i-k) Immunofluorescence for PC1 and vimentin in the medulla of a 2-week kidney. (I-n) Higher magnification of outlined area in (i-k), respectively. (o-q) Immunofluorescence for PC1 and vimentin in the cortex of a 2-week kidney. Scale bar: $100 \mu \mathrm{m}$; scale bar in (c) applies to (c-q). ep, epithelium; vmt, vimentin; w, week. 

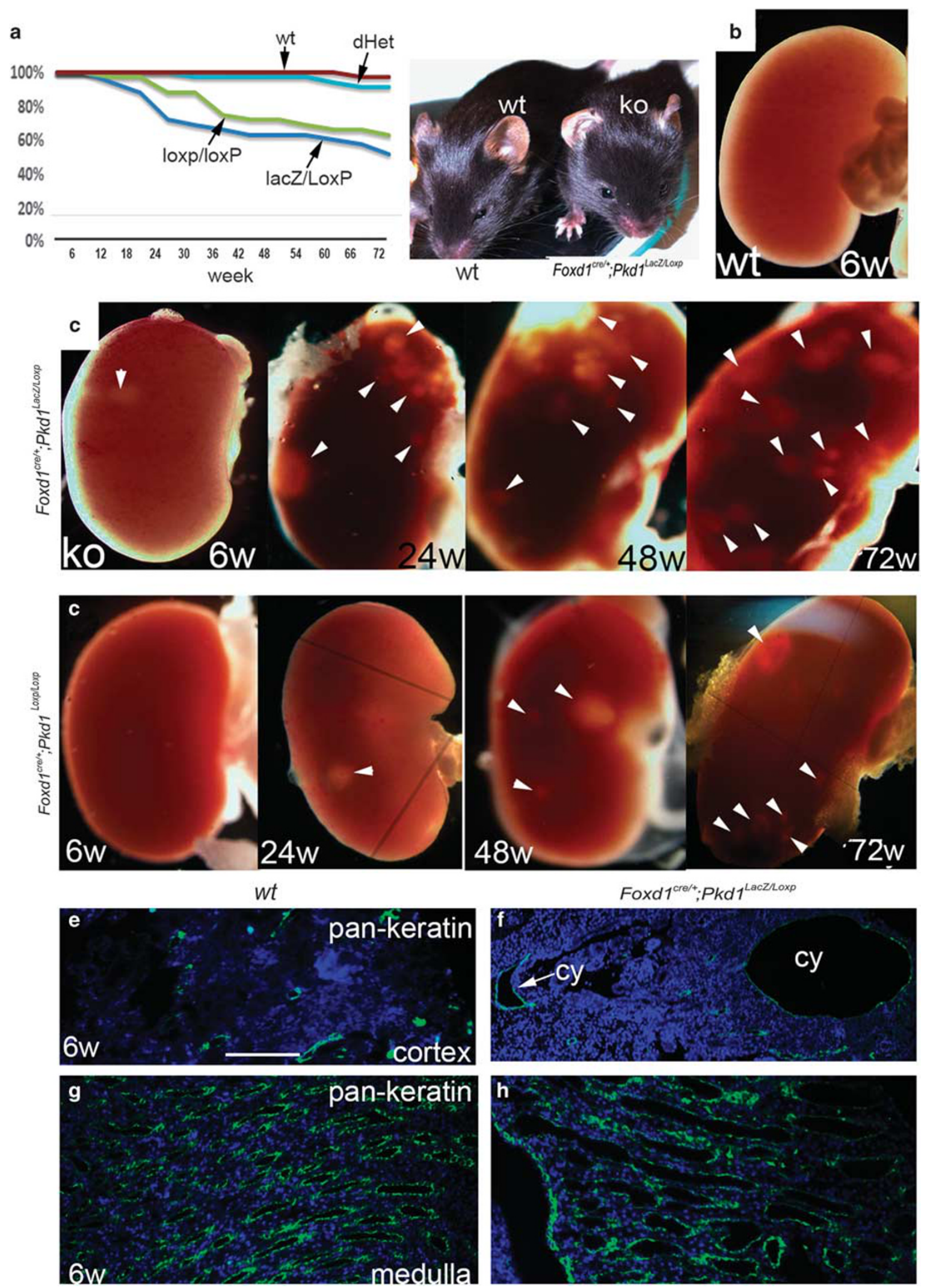

Figure 2 Phenotype of Foxd $1^{\text {Cre/+}}$;Pkd $1^{\text {LoxP/LoxP }}$ mice and Foxd ${ }^{\text {Cre/+ }}$;Pkd $1^{\text {LacZ/LoxP }}$ mice. (a) Appearance of Foxd $1^{\text {Cre/+}}$;Pkd ${ }^{\text {LacZ/LoxP }}$ mice at 6 weeks of age and survival data of the two lines of knockout mice, $n=30$ for each genotype. (b) A wild-type kidney. (c) Kidneys of Foxd ${ }^{\text {Cre/+ }} ;$;Pkd $1^{\text {LacZ/LoxP }}$ mice at successive ages. (d) Kidneys of Foxd $1^{\text {Cre/ }+} ;$;Pkd $1^{\text {LoxP/LoxP }}$ mice at successive ages. (e-h) Pan-cytokeratin staining of control and Foxd $1^{\text {Cre/t }} ;$;Pkd $1^{\text {Lacz/LoxP }}$ kidneys. Scale bar: $100 \mu \mathrm{m}$. dHet, Foxd ${ }^{\text {Cre/+ }} ;$; $P k d 1^{\text {LacZ/+ }}$ double heterozygous mice; KO, knockout; w, week; wt, wild type; yr, year. 
Increased Proliferation and Apoptosis in Mutant Kidneys Increased apoptosis and proliferation are hallmarks of cellular changes in polycystic kidneys. ${ }^{43-45}$ We therefore examined apoptosis and proliferation by TUNEL and phospho-Histone H3 staining. Phospho-Histone H3 staining showed that cell proliferation ratios at 2-week stage remained comparable

\begin{tabular}{|c|c|}
\hline Phenotype & Penetrance \\
\hline Dome-shape head & $80 \%(16 / 20)$ \\
\hline Short snout & $100 \%(20 / 20)$ \\
\hline Malocclusion & $30 \%(6 / 20)$ \\
\hline Growth retardation & $45 \%(9 / 20)$ \\
\hline \multicolumn{2}{|l|}{ Infertility } \\
\hline Male & $90 \%(9 / 10)$ \\
\hline Female & $90 \%(9 / 10)$ \\
\hline Spine curvature disorders & $5 / 20(25 \%)$ \\
\hline Kidney cysts & $100 \%(20 / 20)$ \\
\hline
\end{tabular}

between mutants and controls (Figure $4 \mathrm{a}, \mathrm{b}$ and g). In adult kidneys, cell proliferation ratios were very low in controls, but were significantly higher in mutant kidneys (Figure $4 \mathrm{c}-\mathrm{g}$ ). Co-localization of phospho-Histone $\mathrm{H} 3$ with epithelial marker pan-cadherin and pan-cytokeratin revealed that proliferative cells were predominately located in epithelia rather than the stromal compartment (Figure $4 \mathrm{~h}$ and i).

TUNEL staining revealed vigorous apoptosis in the cortex and medulla of mutant kidneys in both postnatal development stages and adulthood (Figure $4 \mathrm{j}-\mathrm{q}$ ). Increased apoptosis was not only found in the interstitium and capsule but also in the epithelium, suggesting that multiple cell types were affected (Figure $4 \mathrm{k}, \mathrm{m}, \mathrm{o}$ and $\mathrm{q}$ ). In sum, apoptosis and proliferation were both increased in mutant kidneys.

\section{Defects in the Interstitium, Basement Membrane and Renal Capsule of Mutant Kidneys}

Next, we examined the renal stromal compartment in mutant mice. Mesenchymal cell marker vimentin staining revealed reduced amount of mesenchymal cells in both cortex and medulla of mutant kidneys compared with controls at 2-week stage (Figure 4r-v). An important type of cells derived from renal stromal cells are the interstitial fibroblasts, which form
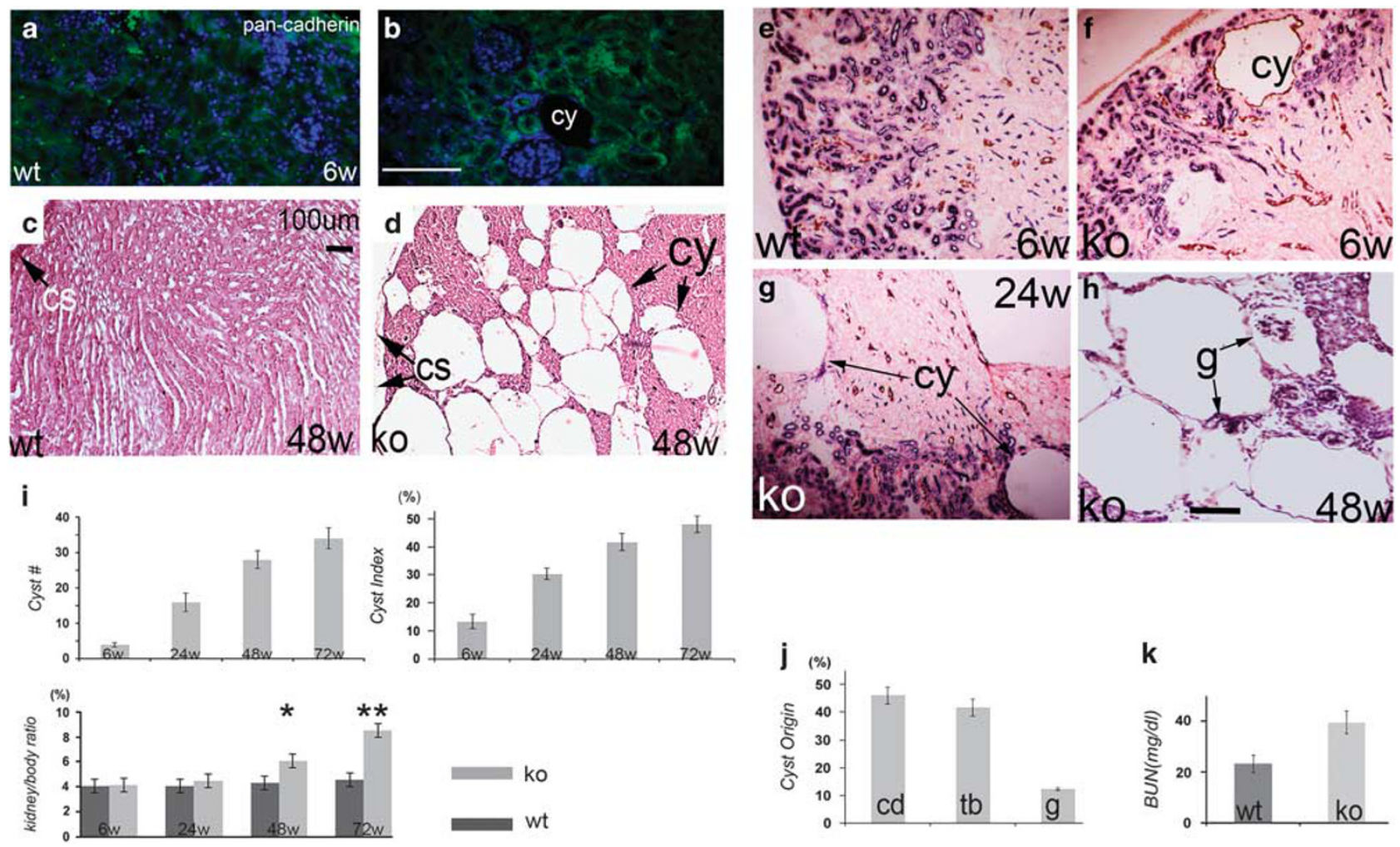

Figure 3 Progressive renal cyst formation in Foxd ${ }^{\mathrm{Cre} /+} ;$; Pkd $1^{\text {LacZ/LoxP }}$ mice. (a, b) Immunofluorescence for pan-cadherin in 6 -week kidney cortex demonstrating rare cystic tubules. (c, d) Histology of control and mutant kidneys at 48 weeks. Note the abundance of cysts in the mutant kidney. (e-g) Dual staining of E-cadherin (NBT/BCIP, blue) and DBA lectin (DAB, brown) in wild-type control and mutant kidneys. (h) Histology of a mutant kidney showing glomerular urinary space dilation. (i) Cyst numbers, cyst index and kidney/body weight ratios at successive stages. ${ }^{*} P<0.05$, ${ }^{*} P<0.01$. (j) $C y s t$ origins at 24-week stage. (k) BUN levels of 72-week old mice, $P<0.05$. Scale bar: $100 \mu \mathrm{m}$. cd, collecting duct; cs, capsule; cy, cyst; g, glomerulus; ko, knockout; tb, tubule; w, week; wt, wild type. 

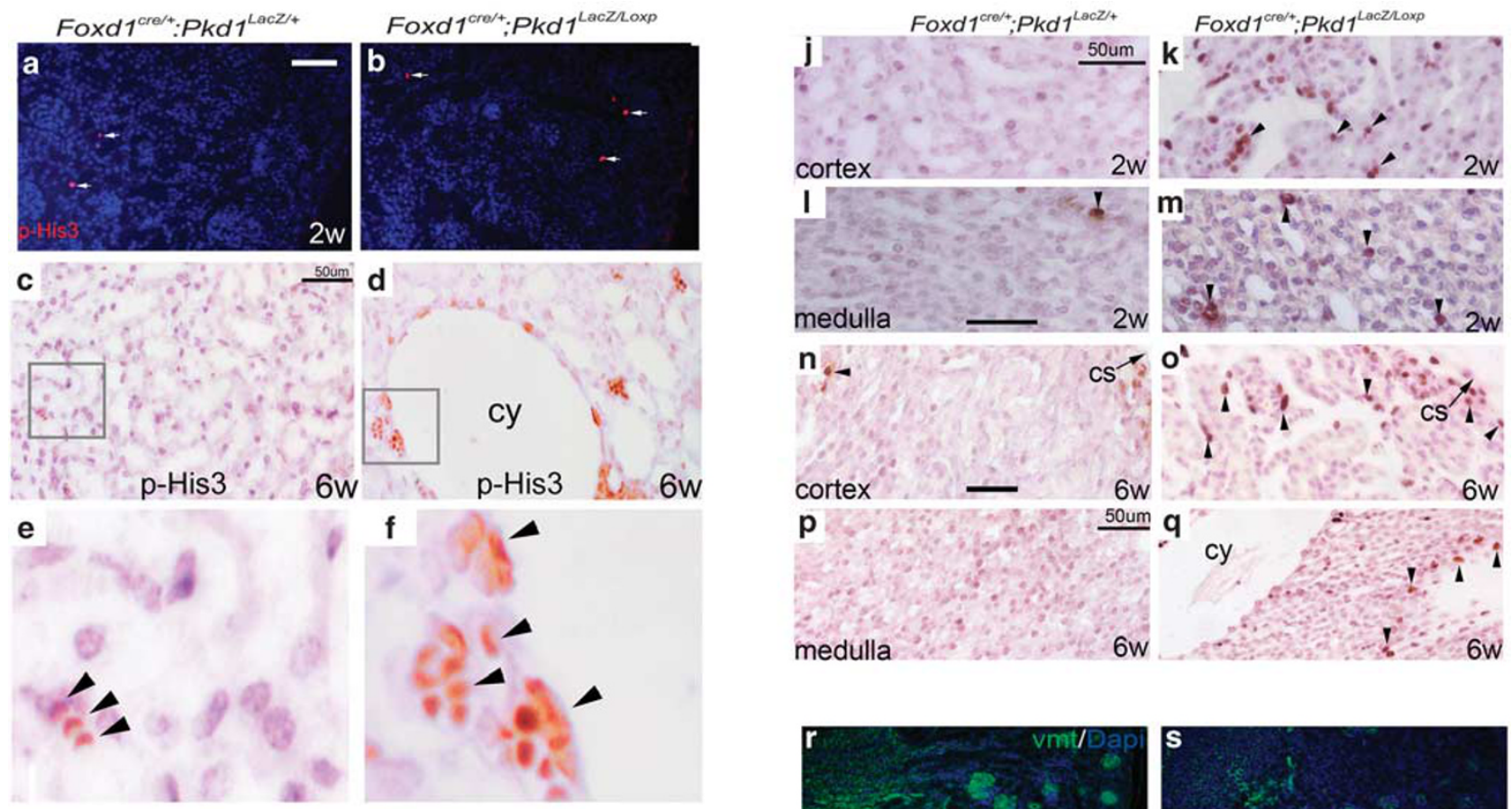

g

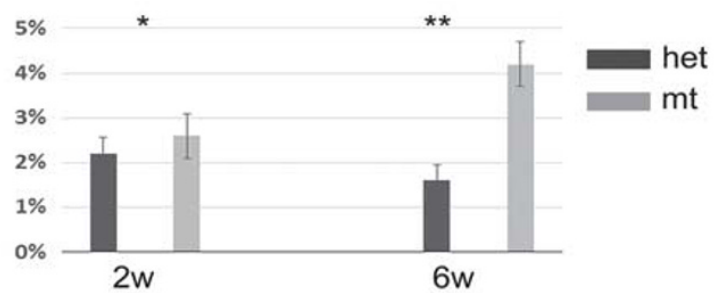

p-His3/Dapi

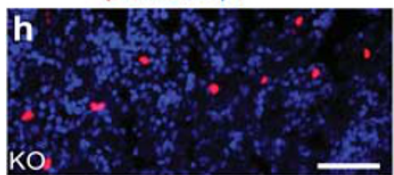

p-His3/pan-cadherin/pan-keratin/Dapi

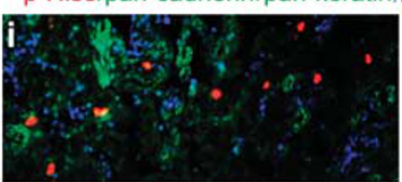

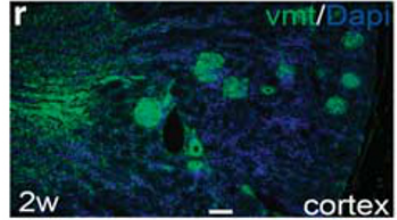
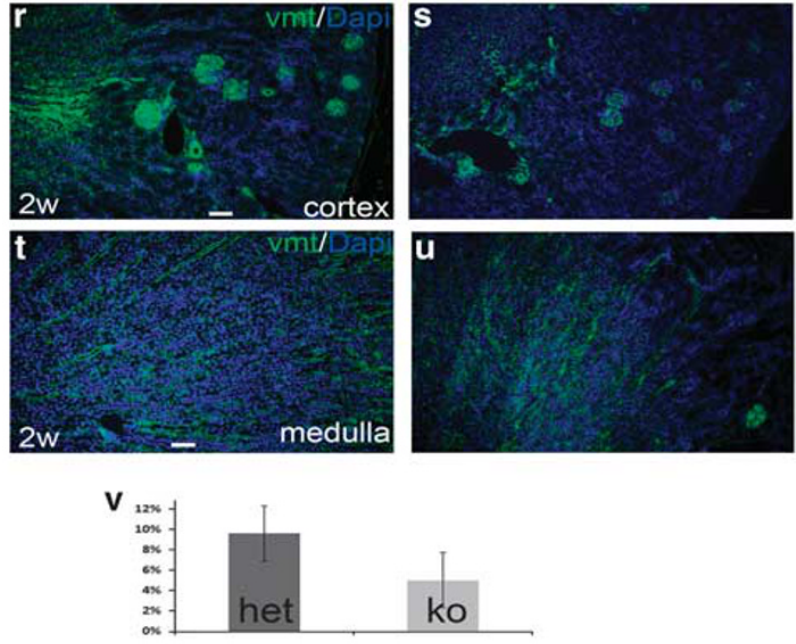

Figure 4 Phospho-Histone H3, TUNEL and vimentin staining. (a, b) Phospho-Histone H3 staining at 2-week stage kidney, showing comparative proliferation in both genotypes. (c, d) Phospho-Histone $\mathrm{H} 3$ staining at 6-week stage kidney, showing active mitosis in mutant. (e, f) Higher power of boxed areas in (c) and (d). (g) Proliferation ratios of mutants and controls, ${ }^{*} P>0.05$; ${ }^{*} P<0.01$. (h, i) Immunofluorescence of phospho-Histone H3, pancytokeratin and pan-cadherin in mutant, showing that proliferative cells are predominately in epithelia. (j-m) TUNEL staining at 2-week stage, showing active apoptosis in the cortex and medulla of mutant kidneys. (n-q) TUNEL staining at 6-week stage, showing active apoptosis in the cortex and medulla of mutant kidneys. ( $\mathbf{r}-\mathbf{u})$ Vimentin staining in the cortex and medulla. (v) Quantification of vimentin stained area versus total area, showing reduced mesenchymal tissue in mutant. Scale bar: $50 \mu \mathrm{m}$. cs, capsule; cy, cyst; het, heterozygous control; ko, knockout; p-His3, phospho-Histone H3; vmt, vimentin; w, weeks.

and maintain the interstitium by depositing and remodeling ECM. Masson's trichrome stain showed that ECM components were markedly deficient in both cortex and medulla of mutant kidneys in young adult mice, implying that the interstitium was inappropriately formed (Figure 5a-d). Consistently, levels of type I collagen, the most abundant component of renal ECM, were visibly reduced in both renal cortex and medulla in young adult mice (Figure 5e-h). Similarly, levels of fibronectin, another important component of renal ECM, were also reduced in mutant kidneys (Figure $5 \mathrm{i}$ and $\mathrm{j}$ ). These observations were confirmed by western blot analysis (Figure 5k).

The basement membrane (BM) is critical for maintaining epithelial cell homeostasis. BM defects can induce abnormal cell proliferation and cause cystogenesis in mouse kidneys. ${ }^{46}$ Further, BM abnormalities are common in ADPKD. ${ }^{32,47,48}$ Here we examined two major components of the BM, type IV collagen and laminin. We found that levels of type IV collagen were significantly decreased compared with controls (Figure 5k, 1 and $\mathrm{m}$ ). It was often absent in developing cysts 

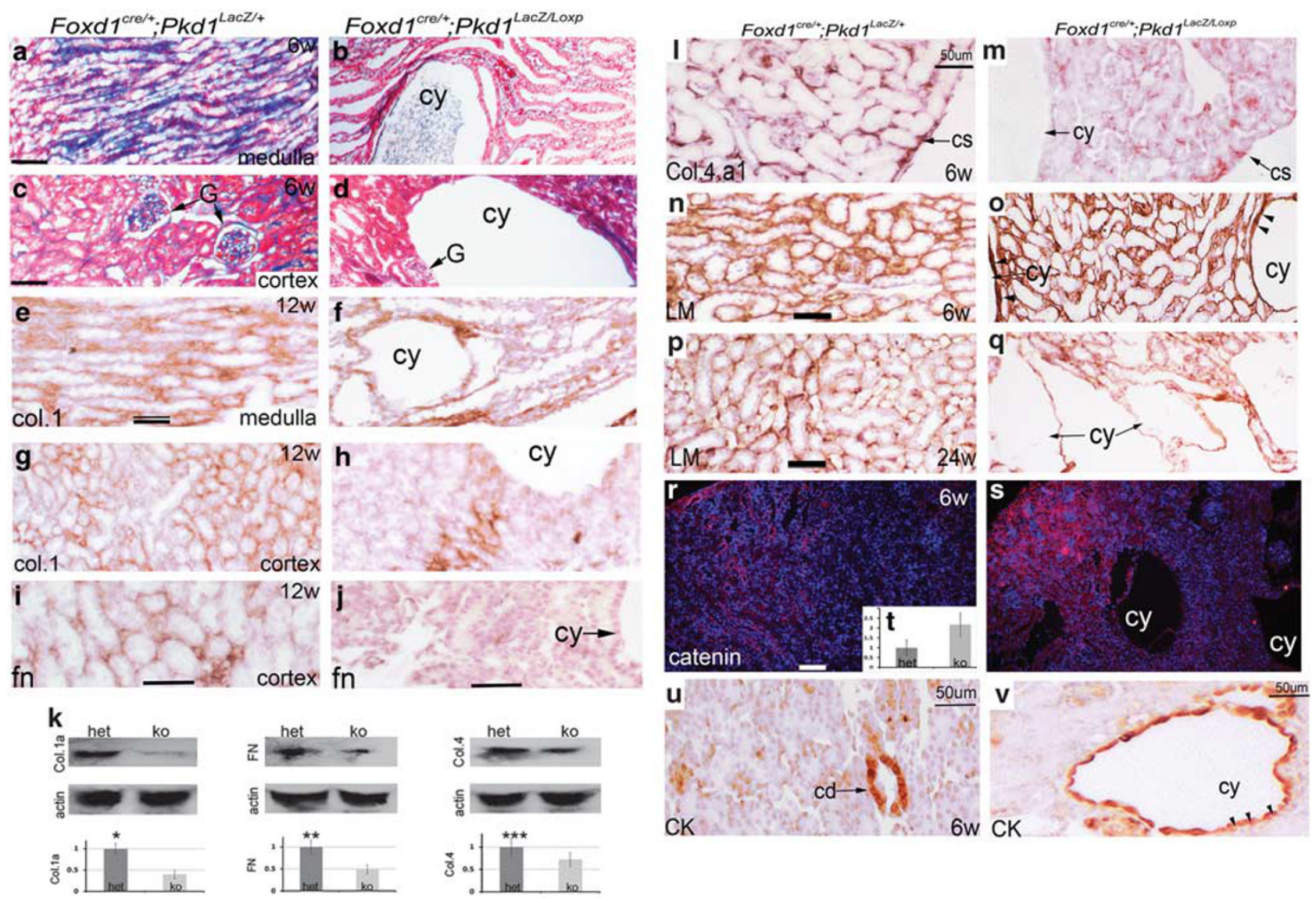

Figure 5 Extracellular matrix and epithelial changes of $\mathrm{Foxd}_{1}{ }^{\mathrm{Cre} /+}$; $P$ Pd $11^{\text {Lacz/LoxP }}$ kidneys. (a-d) Masson's trichrome staining, revealing reduction of extracellular matrix (blue) in the renal medulla and cortex of mutant mice. (e-h) Immunostaining for $a 1$ type I collagen, showing reduction of $a 1$ type I collagen in the cortex and medulla of mutant kidneys. (i, j) Immunostaining for fibronectin, showing reduction of fibronectin in mutant kidney. (k) Western blots for $a 1$ type I collagen, fibronectin and $a 1$ type IV collagen of 12-week-old mice; bars represent relative levels of band density, ${ }^{*} P<0.001$, ${ }^{* *} P<0.001 ;{ }^{* *} P<0.01$. (I, $\left.\mathbf{m}\right)$ Immunostaining for type IV collagen, showing reduction of type IV collagen in the mutant. (n, o) Immunostaining for laminin, revealing focal thickening of the basement membrane in the mutant as indicated by arrow heads. (p, q) Immunostaining for laminin, showing discontinuity of the basement membrane in the mutant. $(\mathbf{r}, \mathbf{s})$ Immunostaining for $\beta$-catenin. (t) qRT-PCR for $\beta$-catenin, $P<0.001$. (u, $\mathbf{v})$ Pan-cytokeratin staining, showing cell shape change in cyst epithelial cells (arrow heads). Scale bar: $50 \mu \mathrm{m}$. cd, collecting ducts; CK, pan-cytokeratin; col.1, type I collagen; col.4, type IV collagen; cs, capsule; cy, cyst; fn, fibronectin; g, glomerulus; het, Foxd ${ }^{\text {Cre/ }}$;Pkd1 ${ }^{\text {Lacz/+ }}$ heterozygous control; ko, knockout; LM, laminin; $w$, weeks.

(Figure $5 \mathrm{l}$ and $\mathrm{m}$ ). Laminin staining did not show any decrease at young adult stage, but revealed focal thickening of the $\mathrm{BM}$ in cysts (Figure $5 \mathrm{n}$ and $\mathrm{o}$ ). At an advanced stage, we detected reduced BMs in many cysts (Figure 5p and q).

The renal capsule is also formed and maintained by stromal cells. Here we found that, in mutant kidneys, the renal capsule was thin and displayed increased apoptosis (Figures $3 \mathrm{~b}$ and g, $4 \mathrm{n}$ and $\mathrm{o}$ ). It was also deficient of collagens (Figure $5 \mathrm{l}$ and $\mathrm{m}$ ). Altogether, these results indicate essential roles of PC1 in development and maintenance of stromal cell derivatives, including the renal interstitium, BM and capsule.

\section{Epithelial Changes in Mutant Kidneys}

An association between upregulation of $W n t / \beta$-catenin signaling and cystic change has been reported in polycystic kidneys. ${ }^{49}$ Here, we examined levels of $\beta$-catenin, an intracellular mediator for canonical Wht signaling.
Immunostaining showed a visible increase of $\beta$-catenin levels in pre-cystic renal epithelia in young adult mice (Figure $5 \mathrm{r}$ and s). Real-time PCR showed that $\beta$-catenin levels of mutant kidneys increased by twofold compared with controls (Figure 5t). These results indicate an upregulation of Wnt signaling in mutant kidneys. Cell shape change was evident in cyst-lining epithelia. Epithelial cells mostly transformed from cuboidal cells to flat cells in cysts, as labeled with pancytokeratin staining (Figure $5 \mathrm{u}$ and $\mathrm{v}$ ).

\section{Renal Vasculature Defects in Mutant Kidneys}

Renal stromal cells are important for renal vasculature development and maintenance. ${ }^{36,50}$ Vascular abnormalities are very common in ADPKD. ${ }^{51,52}$ Here we found that the smooth muscle layers of mutant arteries were thin and disorganized compared with controls, as indicated by $\alpha$-SMA staining (Figure $6 \mathrm{a}$ and $\mathrm{b}$ ). Immunostaining for type IV 

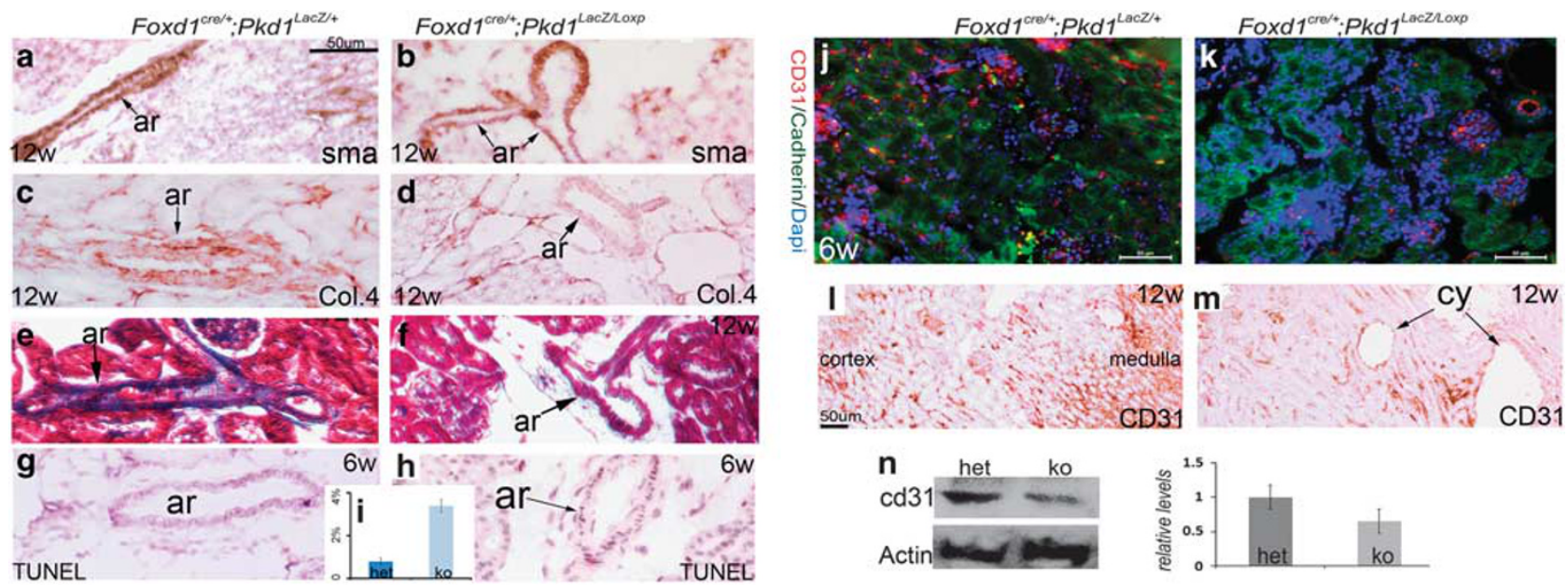

Figure 6 Vasculature changes in Foxd $1^{\mathrm{Cr} /+} ;$; $P k d 1^{\text {LacZ/LoxP }}$ kidneys. (a, b) Immunostaining for a-smooth muscle actin. (c, d) Immunostaining for type IV collagen. (e, f) Masson's trichrome staining, revealing extracellular matrix reduction in the mutant artery. (g, h) TUNEL staining, showing increased apoptosis in mutant renal artery. (i) Apoptosis ratios of mutant and control, $P<0.001$. (j, k) Immunofluorescence for CD31 at 6-week stage. (I, $\mathbf{m}$ ) Immunohistochemistry for CD31 at 12-week stage. Note the vascular components are markedly reduced in the mutant. (n) Western blot for CD31 at 12 week stage, $P<0.01$. Scale bar: $50 \mu \mathrm{m}$. Scale bar in (a) applies to (a-h). ar, artery; Col.4, type IV collagen; cy, cyst; het, Foxd $1^{\text {Cre/ }} ;{ }^{\text {Pkd }}{ }^{\text {Lacz/+ }}$ heterozygous control; ko, knockout; sma, alpha smooth muscle actin; w, weeks.

collagen and Masson's trichrome staining revealed visible ECM reduction in mutant arteries (Figure 6c-f). TUNEL staining also showed abnormal apoptosis in mutant vessel walls (Figure $6 \mathrm{~g}-\mathrm{i})$. These results indicate that the vessel wall, a derivative of renal stromal cells, was affected in mutant kidneys.

We further examined the renal capillary system using an antibody for CD31, an endothelial cell marker. CD31-stained vascular structures were abundant in controls but fewer in mutants (Figure 6j-m). Western blot confirmed this finding (Figure $6 \mathrm{n}$ ). These results indicate that disruption of $P k d 1$ in stromal cells affected the peritubular capillary system.

\section{DISCUSSION}

Compared with the epithelium, we still know very little regarding functional roles of ADPKD genes in stromal cell derivatives, including the renal capsule, interstitium, mesangium, and vascular wall. Recently, new and emerging roles of ADPKD genes for the stromal compartment in kidney diseases are being revealed. ${ }^{36}$ Here we took advantage of the Foxd1 $1^{\text {GFP-Crel+ }}$ mice to dissect roles of Pkd1/PC1 in stromal cell derivatives. Foxd1 is a critical transcription factor for renal stromal cell development. Its expression is detected as early as kidney morphogenesis initiates. Foxd1-driven Cre line has been tested and used in a number of recent studies. ${ }^{34,50,53-57}$ Compelling evidence shows that Foxd1 $1^{\text {GFP-Cre/t }}$ mouse is a very specific Cre line for renal stromal cells. ${ }^{34,50,53-57}$ Even in adulthood, activity of Foxd1-driven Cre is still faithfully restricted to the stromal compartment in the kidney. ${ }^{34,57}$

In this study, we established Foxd $1^{e G F P-C r e /+} ; P k d 1^{\text {LoxP/LoxP }}$ and Foxd ${ }^{\text {GFFP-Cre/ }} ;$; $P d 1^{\text {LacZ/LoxP }}$ mutant mouse models. Although both lines show renal stromal defects and cyst formation, phenotypes in Foxd $1^{\text {eGFP-Cre/+}} ;$ Pkd1 $1^{\text {LacZ/LoxP }}$ mice are more striking than in Foxd ${ }^{\text {eGFP-Cre/+ }} ; P$ Pkd $1^{\text {LoxP/LoxP }}$ mice. This discrepancy might reflect different Cre recombination efficiency in the two mouse lines, and/or that a null copy of $P k d 1$ might contribute to disease manifestation. By disrupting $P k d 1$ from stromal cells, we provide strong evidence to assign a functional role for $P k d 1$ in development and maintenance of stromal cell derivatives and show that cysts form if this function is impaired.

The renal interstitial fibroblasts, which are derived from stromal cells, are responsible for maintaining ECM components in the interstitium. ${ }^{32}$ Multiple lines of evidence suggest that $P k d 1$-encoded PC1 is involved in ECM regulation in a variety of organ systems..$^{25,32,58,59}$ The extracellular domain of PC1 physically interacts with most components of ECM, including collagen, laminin and fibronectin. ${ }^{25,59}$ Thus, PC1 has been proposed as a receptor for ECM components. Our data support this view, as disruption of $P k d 1$ in stromal cells leads to significant ECM reduction in the stromal compartment.

However, the deficiency of ECM in our model contrasts with the renal pathological changes in ADPKD, which is characterized by excessive ECM deposition and progressive fibrosis in late-stage disease. ${ }^{25,32}$ In humans, loss of heterozygosity of an ADPKD gene is a long-term event, and only occurs in a small number of kidney cells. Consistently, cysts arise only from a minority of nephrons in polycystic kidneys. Approximately fewer than 5\% of nephrons are affected in ADPKD. The majority of heterozygous cells may still function properly, and are capable of maintaining the ECM. ${ }^{60}$ Fibrosis associated with ADPKD is likely a responsive reaction of heterozygous fibroblasts to various pathologic changes. One study showed that heterozygous interstitial fibroblasts from 
Table 2 Comparison of cortex and medulla in mutant mice

\begin{tabular}{lll}
\hline & Cortex & Medulla \\
\hline Cyst & $\begin{array}{l}\text { Isolated in young mice, clustered in } \\
\text { aged mice }\end{array}$ & Isolated \\
& No & Common \\
Duct/tubule dilation & Reduced & Reduced \\
ECM & Increased & Increased \\
Apoptosis/proliferation & Decreased \\
Vasculature & Decreased & \\
\hline
\end{tabular}

kidneys of ADPKD patients are even able to overreact to inductive signals. ${ }^{60}$ In our mutant mice, however, interstitial fibroblasts are mostly, if not all, $P k d 1$-null and are defective in interacting with ECM components. Thus, these Pkd1-null cells are functionally insufficient for physiological activities, and a number of these cells adopt an apoptotic fate causing significant reduction in interstitial tissue.

It is noteworthy that stromal PC1 disruption affected both renal cortex and medulla. Interstitial tissue reduction, increased apoptosis/proliferation and cyst formation were detected in both compartments. However, disease manifestation varied in the two compartments. Cysts in the cortex clustered as mice aged, while medullary cysts mostly remained isolated (Table 2). Furthermore, collecting system dilation was common in the medulla (Table 2).

Multiple lines of evidence support that fibroblast defects cause BM abnormalities. ${ }^{35,44,45}$ The BM, mainly composed of laminin and type IV collagen, is a thin layer of a specialized ECM directly underlying epithelial cells. Maintenance of the BM requires both the overlying epithelial cells and the underlying interstitial cells. Functional deficiency of $P k d 1$-null interstitial cells might induce compensatory activity of epithelial cells, explaining local thickening in BM in early adult stage. However, epithelium alone is not sufficient for long-term BM maintenance and will eventually fail to maintain BM integrity. BM defects caused by $P k d 1$ disruption in stromal cells may serve as a critical pathogenic mechanism for cystogenesis in this model. Indeed, interactions between epithelial cells and BM components such as laminin are of critical importance for epithelial cell homeostasis. BM defects caused by laminin mutation alone are sufficient to induce cystogenesis in mice. ${ }^{46}$ Moreover, $\mathrm{BM}$ abnormalities are common in various PKD models and human ADPKD. ${ }^{46,61}$ Altered interactions between epithelial cells and BMs may account for the increase of beta-catenin levels and cell proliferation in mutant epithelium, and subsequent initiation of cystogenesis. Interestingly, increased expression of betacatenin was mostly seen in pre-cystic epithelium, suggesting that increase of Wnt signaling may be a common pathway for initiation of cystogenesis. ${ }^{49}$ It is possible that abnormal cell apoptosis in epithelia is also caused by altered BM-epithelium interactions. Thus, abnormal BM change might be a fundamental mechanism underlying cystogenesis, and it can arise from defects either in epithelia or in the stromal compartment.

However, it is also possible that epithelium defects are directly caused by compromised stromal-epithelial interactions, which are critical for structural integrity of kidneys in multiple settings. For instance, disruption of stromal cells by inactivation of Foxd1 arrests kidney development at a very early stage leading to renal agenesis or formation of rudimentary kidneys, suggesting stromal-epithelial crosstalk plays an essential role for kidney development. ${ }^{62}$ Less severe stromal cell defects, however, cause cystogenesis during kidney development as evidenced in $T b \times 18^{-/-}$mice, further supporting that stromal cell changes alone are sufficient to induce cystogenesis. ${ }^{63}$

Vascular abnormalities are implicated in a variety of kidney diseases including ADPKD. ${ }^{64}$ In ADPKD kidneys, vascular malformation and remodeling are not uncommon, suggesting that vascular changes might be a contributing factor for renal pathogenesis. ${ }^{64}$ Functional roles of $P k d 1$ in the vascular system have been firmly established. ${ }^{28,52,65-67}$ Here we show that PC1 functions in stromal cell derivatives are important for maintaining the renal vasculature. Foxd1+-derived cells directly participate in renal vascular system development via differentiating into vascular smooth muscle cells and pericytes, and are critical to maintain endothelial integrity. ${ }^{36,50}$ A recent study suggests that Foxd1+ cells may also be a source of endothelial cells during kidney development. ${ }^{68}$ If so, Foxd1-driven Cre would directly target both the endothelium and its associated tissue. In this work, we found vascular changes in PC1-deficient kidneys, accompanied by stromal and epithelial changes. A key feature is development of microvascular regression and rarefaction, a common pathway in ESRD. Importantly, vascular changes are not limited to cystic areas, further supporting that vascular changes are primary defects and independent of cyst formation in PC1-deficient kidneys. Phenotypic analysis of $P k d 1$ null mice demonstrate that PC1 is not only important for vasculature maintenance but also critical for its development. ${ }^{67}$ Disruption of Pkd1 causes malformation of vessels and vascular leakage in the kidney and other systems. Interestingly, similar vascular defects have also been found in $T b \times 18^{-/-}$kidneys, in which stromal cell defects serve as the primary mechanism for kidney defects. ${ }^{37}$ Altogether, these data demonstrate stromal cells and their derivitives are critical for vasculature development and maintenance.

Previously reported models, including several using inducible systems, primarily target epithelial $P k d 1 .{ }^{21-23}$ By contrast, this model targets renal stromal cells and their derivatives. PC1 deficiency in the stromal compartment leads to a slow progression of cystogenesis in adulthood that does not affect kidney function in young mice. The phenotype models major facets of human ADPKD and allows us to address tissue specific roles of PC1. With this model, we provide robust evidence to assign a critical role for $P k d 1 / \mathrm{PC} 1$ in maintaining stromal cell derivatives. Our study indicates 
that stromal compartment defects caused by PC1 deficiency may serve as a critical mechanism for cyst formation, and might contribute significantly to renal pathogenesis in human ADPKD.

\section{ACKNOWLEDGMENTS}

This work was supported by a generous donation from the Lillian Goldman Charitable Trust and a grant (to XN) from the National Kidney Foundation of Maryland.

\section{DISCLOSURE/CONFLICT OF INTEREST}

The authors declare no conflict of interest.

1. Brasier JL, Henske EP. Loss of the polycystic kidney disease (PKD1) region of chromosome $16 \mathrm{p} 13$ in renal cyst cells supports a loss-offunction model for cyst pathogenesis. J Clin Invest 1997;99:194-199.

2. Koptides M, Constantinides R, Kyriakides G, et al. Loss of heterozygosity in polycystic kidney disease with a missense mutation in the repeated region of PKD1. Hum Genet 1998;103:709-717.

3. Hopp K, Ward CJ, Hommerding CJ, et al. Functional polycystin-1 dosage governs autosomal dominant polycystic kidney disease severity. J Clin Invest 2012;122:4257-4273.

4. Sharif-Naeini R, Folgering JH, Bichet $\mathrm{D}$, et al. Polycystin- 1 and -2 dosage regulates pressure sensing. Cell 2009;139:587-596.

5. Lantinga-van Leeuwen IS, Dauwerse JG, Baelde HJ, et al. Lowering of Pkd1 expression is sufficient to cause polycystic kidney disease. Hum Mol Genet 2004;13:3069-3077.

6. Takakura A, Contrino L, Zhou X, et al. Renal injury is a third hit promoting rapid development of adult polycystic kidney disease. Hum Mol Genet 2009;18:2523-2531.

7. Weimbs T. Third-hit signaling in renal cyst formation. J Am Soc Nephrol 2011;22:793-795.

8. Gonzalez-Perrett $S$, Kim K, Ibarra C, et al. Polycystin-2, the protein mutated in autosomal dominant polycystic kidney disease (ADPKD), is a Ca2+-permeable nonselective cation channel. Proc Natl Acad Sci USA 2001;98:1182-1187.

9. Koulen $\mathrm{P}$, Cai $Y$, Geng $\mathrm{L}$, et al. Polycystin-2 is an intracellular calcium release channel. Nat Cell Biol 2002;4:191-197.

10. Qian F, Germino FJ, Cai Y, et al. PKD1 interacts with PKD2 through a probable coiled-coil domain. Nat Genet 1997;16:179-183.

11. Xu GM, Gonzalez-Perrett S, Essafi M, et al. Polycystin-1 activates and stabilizes the polycystin-2 channel. J Biol Chem 2003;278:1457-1462.

12. Nauli SM, Alenghat FJ, Luo $\mathrm{Y}$, et al. Polycystins 1 and 2 mediate mechanosensation in the primary cilium of kidney cells. Nat Genet 2003;33:129-137.

13. Nauli SM, Rossetti S, Kolb RJ, et al. Loss of polycystin-1 in human cystlining epithelia leads to ciliary dysfunction. J Am Soc Nephrol 2006;17: 1015-1025.

14. Yoder BK, Hou X, Guay-Woodford LM. The polycystic kidney disease proteins, polycystin-1, polycystin-2, polaris, and cystin, are co-localized in renal cilia. J Am Soc Nephrol 2002;13:2508-2516.

15. Yoder BK, Mulroy $\mathrm{S}$, Eustace $\mathrm{H}$, et al. Molecular pathogenesis of autosomal dominant polycystic kidney disease. Expert Rev Mol Med 2006;8:1-22.

16. Ong AC, Wheatley DN. Polycystic kidney disease-the ciliary connection. Lancet 2003;361:774-776.

17. Patel V, Li L, Cobo-Stark $\mathrm{P}$, et al. Acute kidney injury and aberrant planar cell polarity induce cyst formation in mice lacking renal cilia. Hum Mol Genet 2008;17:1578-1590.

18. Davenport JR, Watts AJ, Roper VC, et al. Disruption of intraflagellar transport in adult mice leads to obesity and slow-onset cystic kidney disease. Curr Biol 2007;17:1586-1594.

19. Ma $M$, Tian $X$, Igarashi $P$, et al. Loss of cilia suppresses cyst growth in genetic models of autosomal dominant polycystic kidney disease. Nat Genet 2013;45:1004-1012.

20. Delling $M$, Indzhykulian AA, Liu $X$, et al. Primary cilia are not calciumresponsive mechanosensors. Nature 2016;531:656-660.

21. Lantinga-van Leeuwen IS, Leonhard WN, van der Wal A, et al. Kidneyspecific inactivation of the Pkd1 gene induces rapid cyst formation in developing kidneys and a slow onset of disease in adult mice. Hum Mol Genet 2007;16:3188-3196.

22. Takakura A, Contrino L, Beck AW, et al. Pkd1 inactivation induced in adulthood produces focal cystic disease. J Am Soc Nephrol 2008;19: 2351-2363.

23. Piontek K, Menezes LF, Garcia-Gonzalez MA, et al. A critical developmental switch defines the kinetics of kidney cyst formation after loss of Pkd1. Nat Med 2007;13:1490-1495.

24. Priolo C, Henske EP. Metabolic reprogramming in polycystic kidney disease. Nat Med 2013;19:407-409.

25. Drummond IA. Polycystins, focal adhesions and extracellular matrix interactions. Biochim Biophys Acta 2011;1812:1322-1326.

26. Fedeles SV, Gallagher AR, Somlo S. Polycystin-1: a master regulator of intersecting cystic pathways. Trends Mol Med 2014;20:251-260.

27. Nie $\mathrm{X}$, Arend $\mathrm{L}$. Pkd1 is required for male reproductive tract development. Mech Dev 2013;130:567-576.

28. Hassane $\mathrm{S}$, Claij $\mathrm{N}$, Jodar $\mathrm{M}$, et al. Pkd1-inactivation in vascular smooth muscle cells and adaptation to hypertension. Lab Invest 2011;91: 24-32.

29. Boulter C, Mulroy S, Webb S, et al. Cardiovascular, skeletal, and renal defects in mice with a targeted disruption of the Pkd1 gene. Proc Natl Acad Sci USA 2001;98:12174-12179.

30. Nie $\mathrm{X}$, Arend L. Novel roles of Pkd2 in male reproductive system development. Differentiation 2014;87:161-171.

31. Van Adelsberg JS, Frank D. The PKD1 gene produces a developmentally regulated protein in mesenchyme and vasculature. Nat Med 1995;1:359-364.

32. Norman J. Fibrosis and progression of autosomal dominant polycystic kidney disease (ADPKD). Biochim Biophys Acta 2011;1812:1327-1336.

33. Guillaume $R, D^{\prime}$ Agati $V$, Daoust $M$, et al. Murine Pkd1 is a developmentally regulated gene from morula to adulthood: role in tissue condensation and patterning. Dev Dyn 1999;214:337-348.

34. Humphreys $\mathrm{BD}$, Lin $\mathrm{SL}$, Kobayashi $\mathrm{A}$, et al. Fate tracing reveals the pericyte and not epithelial origin of myofibroblasts in kidney fibrosis. Am J Pathol 2010;176:85-97.

35. Kida Y, Duffield JS. Pivotal role of pericytes in kidney fibrosis. Clin Exp Pharmacol Physiol 2011;38:467-473.

36. Li W, Hartwig S, Rosenblum ND. Developmental origins and functions of stromal cells in the normal and diseased mammalian kidney. Dev Dyn 2014;243:853-863.

37. Xu J, Nie X, Cai $\mathrm{X}$, et al. Tbx18 is essential for normal development of vasculature network and glomerular mesangium in the mammalian kidney. Dev Biol 2014;391:17-31.

38. Wilson PD, Hreniuk D, Gabow PA. Abnormal extracellular matrix and excessive growth of human adult polycystic kidney disease epithelia. J Cell Physiol 1992;150:360-369.

39. Bhunia AK, Piontek K, Boletta A, et al. PKD1 induces p21(waf1) and regulation of the cell cycle via direct activation of the JAK-STAT signaling pathway in a process requiring PKD2. Cell 2002;109:157-168.

40. Piontek $K B_{\text {, Huso }} \mathrm{DL}$, Grinberg $\mathrm{A}$, et al. A functional floxed allele of Pkd1 that can be conditionally inactivated in vivo. J Am Soc Nephrol 2004;15:3035-3043.

41. Murata F, Tsuyama S, Suzuki S, et al. Distribution of glycoconjugates in the kidney studied by use of labeled lectins. J Histochem Cytochem 1983;31(Suppl):139-144.

42. Prozialeck WC, Lamar PC, Appelt DM. Differential expression of E-cadherin, $\mathrm{N}$-cadherin and beta-catenin in proximal and distal segments of the rat nephron. BMC Physiol 2004;4:10.

43. Goilav B. Apoptosis in polycystic kidney disease. Biochim Biophys Acta 2011;1812:1272-1280.

44. Chapin HC, Caplan MJ. The cell biology of polycystic kidney disease. J Cell Biol 2010;191:701-710.

45. Woo D. Apoptosis and loss of renal tissue in polycystic kidney diseases. N Engl J Med 1995;333:18-25.

46. Shannon MB, Patton BL, Harvey SJ, et al. A hypomorphic mutation in the mouse laminin alpha5 gene causes polycystic kidney disease. J Am Soc Nephrol 2006;17:1913-1922.

47. Calvet JP. Polycystic kidney disease: primary extracellular matrix abnormality or defective cellular differentiation? Kidney Int 1993;43: 101-108.

48. Grantham JJ, Mulamalla S, Swenson-Fields KI. Why kidneys fail in autosomal dominant polycystic kidney disease. Nat Rev Nephrol 2011;7:556-566. 
49. Wuebken A, Schmidt-Ott KM. WNT/beta-catenin signaling in polycystic kidney disease. Kidney Int 2011;80:135-138.

50. Hum S, Rymer C, Schaefer C, et al. Ablation of the renal stroma defines its critical role in nephron progenitor and vasculature patterning. PLoS ONE 2014;9:e88400.

51. Grantham JJ, Mulamalla S, Grantham CJ, et al. Detected renal cysts are tips of the iceberg in adults with ADPKD. Clin J Am Soc Nephrol 2012;7: 1087-1093.

52. Rossetti S, Harris PC. The genetics of vascular complications in autosomal dominant polycystic kidney disease (ADPKD). Curr Hypertens Rev 2013;9:37-43.

53. Kobayashi A, Mugford JW, Krautzberger AM, et al. Identification of a multipotent self-renewing stromal progenitor population during mammalian kidney organogenesis. Stem Cell Rep 2014;3:650-662.

54. Das A, Tanigawa S, Karner CM, et al. Stromal-epithelial crosstalk regulates kidney progenitor cell differentiation. Nat Cell Biol 2013;15: 1035-1044.

55. Nakagawa N, Xin C, Roach AM, et al. Dicer1 activity in the stromal compartment regulates nephron differentiation and vascular patterning during mammalian kidney organogenesis. Kidney Int 2015;87:1125-1140.

56. Duffield JS, Humphreys BD. Origin of new cells in the adult kidney: results from genetic labeling techniques. Kidney Int 2011;79:494-501.

57. Rojas A, Chang FC, Lin SL, et al. The role played by perivascular cells in kidney interstitial injury. Clin Nephrol 2012;77:400-408.

58. Mangos S, Lam PY, Zhao A, et al. The ADPKD genes $p k d 1 \mathrm{a} / \mathrm{b}$ and $p k d 2$ regulate extracellular matrix formation. Dis Model Mech 2010;3: 354-365.
59. Malhas AN, Abuknesha RA, Price RG. Interaction of the leucine-rich repeats of polycystin-1 with extracellular matrix proteins: possible role in cell proliferation. J Am Soc Nephrol 2002;13:19-26.

60. Kuo NT, Norman JT, Wilson PD. Acidic FGF regulation of hyperproliferation of fibroblasts in human autosomal dominant polycystic kidney disease. Biochem Mol Med 1997;61:178-191.

61. Kanwar YS. Revisiting basement membrane pathology in renal cystic disease. J Am Soc Nephrol 2010;21:548-549.

62. Hatini V, Huh SO, Herzlinger D, et al. Essential role of stromal mesenchyme in kidney morphogenesis revealed by targeted disruption of Winged Helix transcription factor BF-2. Genes Dev 1996;10:1467-1478.

63. Airik R, Bussen M, Singh MK, et al. Tbx18 regulates the development of the ureteral mesenchyme. J Clin Invest 2006;116:663-674.

64. Wei W, Popov V, Walocha JA, et al. Evidence of angiogenesis and microvascular regression in autosomal-dominant polycystic kidney disease kidneys: a corrosion cast study. Kidney Int 2006;70:1261-1268.

65. Garcia-Gonzalez MA, Outeda P, Zhou Q, et al. Pkd1 and Pkd2 are required for normal placental development. PLoS ONE 2010;5.

66. Outeda $\mathrm{P}$, Huso DL, Fisher SA, et al. Polycystin signaling is required for directed endothelial cell migration and lymphatic development. Cell Rep 2014;7:634-644.

67. Kim K, Drummond I, Ibraghimov-Beskrovnaya O, et al. Polycystin 1 is required for the structural integrity of blood vessels. Proc Natl Acad Sci USA 2000;97:1731-1736.

68. Sims-Lucas S, Schaefer C, Bushnell D, et al. Endothelial progenitors exist within the kidney and lung mesenchyme. PLoS ONE 2013;8: e65993. 